the production of fly-strips. The industrial strips were produced in a length of 10 or $100 \mathrm{~m}$. and a breadth of 2.5 or $5 \mathrm{~cm}$., and contained 0.5 or $0.7 \mathrm{gm}$. Parathion per strip of $10 \mathrm{~cm}$. $\times 2.5 \mathrm{~cm}$. $(2$ or $2.8 \mathrm{gm}$. per sq. m.). Flies exposed to newly made strips only needed a touch to receive a lethal dose. Strips which had been in use for six months in an air-conditioned room with a temperature of $20^{\circ} \mathrm{C}$. and continuous air renewal killed 100 per cent of the flies after one minute's exposure.

In the summer of 1952 such strips were used in the stables, cowsheds, pigsties, etc., of about 20,000 farms. In the summer of 1953 the strips have been used on between 75,000 and 100,000 farms, to the satisfaction of nearly all the farmers.

The effect only failed in a few cases, particularly where the strips were only used on a single farm in a village; general use eliminated the fly trouble until the end of the season.

The Danish Health Department has permitted the use of the method, and no accidents have been reported. 1 Pimental, D., Schwardt, II. H., and Norton, I. B., Soap and Sanit.
Chem., 1, 27 (1951).

\section{CULTIVATION OF POPLARS}

$\mathrm{T}$ HE wood of poplars has for long been used for making matches, but research work during the present century has shown that it is utilizable in other industries. Mr. T. R. Peace, of the Forestry Commission, describes the work on poplars in Bulletin No. 19 of the Commission*, a publication which supersedes Forest Bulletin No. 5 (1923) and Forestry Commission Leaflet No. 27 on "Poplar Planting" (1948). The chief attraction of the poplar as a tree crop is the rapidity of its growth, for on suitable sites it grows much faster than any other tree hardy in the British Isles; and there is a good market for its timber which, in addition to matches, is used for veneers and other purposes. Propagation, which is usually by cuttings, is easy, and planting and subsequent treatment are also not difficult. The troubles are that the choice of varieties is bewildering and becomes more so with the production of new hybrids; the selection of the site for raising the crop needs care and variations in propagation and tending.

The cradle for the growing of commercial poplars lies in Western Europe, and particularly in France, Belgium and the Netherlands. The main countries with large stands of natural poplar are Sweden, Finland, the United States and Canada. It is with the object of clarifying the central position of poplar propagation and planting that the present bulletin is written, and admirably illustrated. Mr. Peace points out that our knowledge of poplar cultivation and, in particular, of the growing of poplar in woodland or heavily grassed sites is still very far from complete. The traditional practices that have long been followed on the Continent of Furope are not necessarily the best, and in any case may not always be practicable under the conditions met with in Great Britain. The published literature on poplars is very large but is most strictly specialized; only in Holland and Germany are there text.books covering all aspects of poplar cultivation, and these are in the languages of the countries.

* Forestry Commission Bulletin No. 19: Poplars. By T. R. Peace Pp. iv $+50+24$ plates, (Jondon: H.M.S.O., 1952.) 7s. 6 d. net.
The increasing interest in poplar cultivation is evidenced by the number of countries which have formed national poplar commissions to promote the study of poplars and encourage their cultivation. On the initiation of the French, an International Poplar Commission was set up in 1945, holding its first meeting in Paris.

The French peasant in some parts of France has long known the poplar and the rapidity of its growth, and instances are known whereby when a daughter is born the father has planted a few rows of poplars on his land to form her dot when she is married.

'The trees of chief interest are the white poplars, aspens, balsam poplars and black poplars. The bulletin deals with botanical description and choice of variety, sylviculture (site, nursery practice, and planting), diseases and pests (particularly insects and fungi), and properties and uses of poplar timber.

\section{HELICAL STRUCTURE OF CRYSTALLINE DEOXYPENTOSE NUCLEIC ACID}

\author{
By DR. M. H. F. WILKINS
}

Medical Research Council Biophysics Research Unit, King's College, London

AND

DR. W. E. SEEDS, DR. A. R. STOKES and DR. H. R. WILSON

Wheatstone Physics Laboratory, King's College, London

GXACT information about the molecular configuration of deoxypentose nucleic acid may well serve as the basis for understanding its biological function. It has been shown by X-ray diffraction ${ }^{1,2}$ that molecules of deoxyribonucleic acid (in the form of sodium salt) exist probably in a helical configuration when in the paracrystalline state. Proof of the helical structure would be difficult to obtain from the two-dimensional view of the molecule provided by study of paracrystalline material. The regularity of the molecule is so great, however, that it may be crystallized in fibres" ${ }^{\wedge}$, with a remarkably high degree of molecular order, and X-ray study ${ }^{5,6}$ of oriented crystalline deoxyribonucleic acid has enabled a threedimensional view of the geometry of the molecule to be obtained. The purpose of this article is to describe in a preliminary way further three-dimensional data of this kind and to suggest that proof is now available that deoxyribonucleic acid consists of two helical intertwined polynucleotide chains and to show, as a result of molecular model building, that this structure may be of the type suggested by Watson and Crick ${ }^{7}$.

Franklin and Goslings have recently published two- and three-dimensional Patterson diagrams of crystalline calf deoxyribonucleic acid, and by means of these arrived at conclusions in many ways similar to ours. The present work owes much to them and we wish to thank them for making available to us unpublished data. Further work is in progress; clearly all doubts about the basic geometry of deoxyribonucleic acid must be eliminated, for only then can the structural chemistry of its spêcific biological properties and the structure of nucleoprotein be approached on a sound basis. 